\title{
Industrial Agglomeration and Energy Efficiency of Manufacturing Industry
}

\author{
Bo SHI, Xiaoyan ZHANG \\ Northwest University, Xi'an, China \\ 376868734 @q.com, xxyanzhangegmail.com
}

\begin{abstract}
This paper finds that, industry agglomeration cannot exert a positive influence on improving EI and CCR energy efficiency, and the promotion effect on EBM energy efficiency is not significant. Government intervention inhibits the energy conservation effect of industrial agglomeration.
\end{abstract}

Keywords: Energy Conservation, Industrial Agglomeration, Energy Efficiency.

\section{Introduction}

The rapid growth of China's industry is accompanied by a rising level of industrial agglomeration, and the agglomeration level of the industrial sectors in China has increased by $21.3 \%$ in 2015 compared with that in 1978. Industrial agglomeration has a profound impact on economic growth through externalities [4]. Based on this, a large number of studies have revealed the agglomeration effect under different perspectives. Krugman, Glaeser and Fujita pointed out that industrial agglomeration produces positive externalities to enterprises in the same region through technology spill-over and knowledge diffusion effects $[1,2,3]$. O'Sullivan found that the government could build agglomeration by increasing the supplies of local public service infrastructure and industrial infrastructure to attract the investment from manufacturers [5]. At the same time, it is not difficult to find that industrial agglomeration can improve energy efficiency by means of infrastructure sharing and technology spill-over. However, China's industrial development has brought about a sharp increase in energy consumption and environmental pollution. In 2012, energy consumption in the industrial sector accounted for $69.8 \%$ of China's total energy consumption, industrial sulphur dioxide emissions represent $83.9 \%$ for the total emissions, while industrial energy efficiency is much lower than other industries. Industrial agglomeration does not promote energy conservation.

To study the relationship between industrial agglomeration and energy conservation deeply, based on the measurement of energy efficiency of 26 industrial sectors in China from 1999 to 2015, this paper applies SYS-GMM to empirically analyze the relationship between absolute industry agglomeration, relative industrial agglomeration, and energy efficiency. 


\section{Methods}

\subsection{Econometrics model construction}

Based on the analysis of the theoretical model, the authors analyze the relationship between industrial agglomeration and energy efficiency improvement and its mechanism, construct the following dynamic econometrics model considering the inertia of energy efficiency improvement:

$$
E E_{i . t}=\alpha_{0}^{1}+\alpha_{1}^{1} E E_{i, t-1}+\alpha_{2}^{1} A g g_{i, t}+\beta^{1} X_{i, t}+\varepsilon_{i, t}^{1}
$$

Where $i$ represents the industrial sector, $t$ is the year, $\varepsilon_{i, t}$ is the random disturbance, $E E_{i . t}$ refers to the energy efficiency, $A g g_{i, t}$ is the industrial agglomeration variable, $X_{i, t}$ represents a set of control variables.

\subsection{Variables and description of data}

Energy Efficiency ( $E E_{i . t}$ ). This paper applies EBM model to measure the single-factor energy efficiency and total-factor energy efficiency of 26 industrial sectors in China from 1999 to 2015 . Additionally, considering that energy consumption is bound to produce environmental pollution, the DEA method is used to respectively measure the total-factor energy efficiency with and without the undesirable good - the environment pollution. This paper uses three kinds of energy efficiency: energy consumption per unit (EI), total-factor energy efficiency without environmental quality information (CCR), and total-factor energy efficiency with environmental quality information (EBM).

Industrial Agglomeration ( $A g g_{i, t}$ ). The study of industrial agglomeration in the existing literature is relatively abundant, and there are many types of industrial agglomeration indexes. Since this paper examines the impact of spatial geography information of industrial agglomeration on energy efficiency, the index of absolute industrial agglomeration and relative industrial agglomeration is used [6]. The advantage of this index is that it captures the specific geographic concentration that measures the distribution of the industry. At first, the regional share index is defined as:

$$
S_{j, t}^{i}=\frac{X_{j, t}^{i}}{\sum_{j} X_{j, t}^{i}}, S_{j}(t)=\frac{\sum_{i} X_{j, t}^{i}}{\sum_{i} \sum_{j} X_{j, t}^{i}}
$$


$S_{j, t}^{i}$ represents the share of the output value of the $i$ industry accounts for the national $i$ industry in $j$ region in the $t$ year; $S_{j, t}$ represents the share of the output value of all industries accounts for the national industries in $j$ region in the $t$ year. Therefore, the absolute industrial agglomeration $A A_{i, t}$ and the relative industrial agglomeration $R A_{i, t}$ is:

$$
A A_{i . t}=\sum_{i}\left(S_{j, t}^{i}\right)^{2}, R A_{i, t}=\sum_{i}\left(S_{j, t}^{i}-S_{j, t}\right)^{2}
$$

Other control variables. The actual energy price $\left(P_{i, t}\right)$, is the ratio of Purchasing Price Index of Raw Material, Fuel and Power to the Producer Price Index for Industrial Products, and converted to constant price of 1999 as the proxy variable of the actual energy price; Proportion of Foreign Direct Investment $\left(F D I_{i, t}\right)$, to measure the export-oriented level of economy. Economic openness will help improve the energy efficiency. In this paper, the proportion of foreign direct investment is represented as the proportion of the output value of industrial enterprises which include foreign-invested and Hong Kong-Macao-Taiwan invested, accounts for the total output value of the industry. Industry competition $\left(\mathrm{Com}_{i, t}\right)$, the higher the proportion of large and medium-sized enterprises in the industry, the stronger the market power, and the lower the degree of competition, which goes against the innovation and energy efficiency improvement. We use the difference between the ratio that the output value of large and medium-sized industrial enterprises to represent the total industry output value and 1 as the industry competition. Industrial scale $\left(\right.$ Scale $\left._{i, t}\right)$, when there is a scale economy, the average cost of the enterprise decreases with the expansion of the scale, the average output energy conservation embedded in the cost may also decrease, and the energy efficiency is improved. The ratio of the actual output value of the industrial sector to the number of enterprises is the average scale of the industry. Energy conservation dummy variable is another index (Dumy06), and in 2006, the central government for the first time brought the goal of energy conservation and emission reduction into the outline of the national economic development plan. So, the energy conservation dummy variable is added in this model.

To avoid the potential endogeneity problem, this paper uses the system generalized matrix method (SYS-GMM) to empirically analyze the relationship between industrial agglomeration and industrial energy efficiency based on the econometric model (1).

\section{Results}

Equation 1 and 2 in Table 1 shows that the increase in the level of absolute industry agglomeration and relative industrial agglomeration is beneficial to the improvement of energy efficiency in the industrial sector, however, the impact of industrial 
agglomeration does not pass the $10 \%$ of the significance test. To further include the control variables, as shown in Equation 3 and 4, the effect of absolute industry agglomeration and relative industry agglomeration on energy efficiency changes from positive to negative, but remains insignificant. SYS-GMM requires that there is no second-order autocorrelation $\mathrm{AR}(2)$ in difference equations, but allow the existence of first-order autocorrelation AR(1). And the AR test shows that equations 1 to 4 can reject the existence of the second order autocorrelation at the $10 \%$ of significance level, which meets the requirements. In addition, because the dynamic panel data uses several tool variables, we need to do an overidentifying (Sargan) test. Equations 1 to 4 accept the null hypothesis that "all tool variables are valid" and pass the Sargan test.

Equation 5 selects the CCR energy efficiency without environmental quality information as the explanatory variable, and Equation 6 selects the EBM energy efficiency with environmental quality information as the explanatory variable. Relative industrial agglomeration significantly reduces the CCR energy efficiency but will promote the improvement of the EBM energy efficiency, however, this does not pass a significant test. Because industrial agglomerations contain different information, the effect of industrial agglomeration on energy efficiency could have a difference. When the control variables are added, the industrial agglomeration cannot exert a positive effect on the EI and CCR energy efficiency improvement, and the promotion effect on EBM energy efficiency is not significant. Government intervention has inhibited the energy conservation effect of industrial agglomeration. 
Table 1. Estimation Result.

\begin{tabular}{|c|c|c|c|c|c|c|}
\hline $\begin{array}{l}\text { Dependent } \\
\text { Value } \\
E E_{i . t}\end{array}$ & $\begin{array}{l}\text { Equation1 } \\
\text { EI }\end{array}$ & $\begin{array}{l}\text { Equation2 } \\
\text { EI }\end{array}$ & $\begin{array}{l}\text { Equation3 } \\
\text { EI }\end{array}$ & $\begin{array}{l}\text { Equation4 } \\
\text { EI }\end{array}$ & $\begin{array}{l}\text { Equation } 5 \\
\text { CCR }\end{array}$ & $\begin{array}{l}\text { Equation6 } \\
\text { EBM }\end{array}$ \\
\hline$A C_{i, t}$ & $\begin{array}{c}4.2262 \\
(0.43)\end{array}$ & & $\begin{array}{r}-1.5289 \\
(-0.75)\end{array}$ & & & \\
\hline$R C_{i, t}$ & & $\begin{array}{r}9.9943 \\
(0.11)\end{array}$ & & $\begin{array}{r}-0.7666 \\
(-0.31)\end{array}$ & $\begin{array}{c}-0.3403^{* * *} \\
(-3.79)\end{array}$ & $\begin{array}{r}0.4255 \\
\quad(0.83)\end{array}$ \\
\hline$P_{i, t}$ & & & $\begin{array}{c}0.7847 * * * \\
(6.00)\end{array}$ & $\begin{array}{c}0.7745^{* * *} \\
(5.79)\end{array}$ & $\begin{array}{c}0.0581 * * * \\
(11.18)\end{array}$ & $\begin{array}{c}0.085 * * * \\
(7.84)\end{array}$ \\
\hline$S O E_{i, t}$ & & & $\begin{array}{c}0.8885 * * * \\
(3.31)\end{array}$ & $\begin{array}{c}0.9425^{* * * *} \\
(3.66)\end{array}$ & $\begin{array}{c}0.1649^{* * *} \\
(8.35)\end{array}$ & $\begin{array}{c}0.049 * * * \\
(4.04)\end{array}$ \\
\hline$F D I_{i, t}$ & & & $\begin{array}{c}0.8777 * * \\
(2.15)\end{array}$ & $\begin{array}{c}0.6753 * * \\
(2.31)\end{array}$ & $\begin{array}{l}0.1407 * * * \\
(9.91)\end{array}$ & $\begin{array}{c}0.071 * * * \\
(2.78)\end{array}$ \\
\hline$R D_{i, t}$ & & & $\begin{array}{c}2.6133 * * * \\
(6.57)\end{array}$ & $\begin{array}{l}2.5780^{* * * *} \\
(6.51)\end{array}$ & $\begin{array}{c}0.1205^{* * *} \\
(18.58)\end{array}$ & $\begin{array}{r}-0.0139 * \\
(-1.67)\end{array}$ \\
\hline $\operatorname{Com}_{i, t}$ & & & $\begin{array}{c}-1.834 * * * \\
(-5.56)\end{array}$ & $\begin{array}{c}-1.853 * * * \\
(-5.52)\end{array}$ & $\begin{array}{c}0.0393 * * * \\
(3.10)\end{array}$ & $\begin{array}{c}0.0762 * * * \\
(3.85)\end{array}$ \\
\hline Scale $_{i, t}$ & & & $\begin{array}{c}0.0302 * * * \\
(2.99)\end{array}$ & $\begin{array}{c}0.0293 * * * \\
(2.91)\end{array}$ & $\begin{array}{c}-0.0027 * * * \\
(-11.30)\end{array}$ & $\begin{array}{c}-0.005 * * * \\
(-7.76)\end{array}$ \\
\hline Dumy06 & & & $\begin{array}{c}0.1028 * * \\
(2.15)\end{array}$ & $\begin{array}{c}0.1077 * * * \\
(2.27)\end{array}$ & $\begin{array}{r}-0.00007 \\
(-0.07)\end{array}$ & $\begin{array}{c}0.0096 * * * \\
(5.20)\end{array}$ \\
\hline$E E_{i . t-1}$ & $\begin{array}{c}1.085^{* * * *} \\
(31.8)\end{array}$ & $\begin{array}{r}1.091 * * * \\
(14.08)\end{array}$ & $\begin{array}{c}0.8629 * * * \\
(29.83)\end{array}$ & $\begin{array}{c}0.8667 * * * \\
(30.12)\end{array}$ & $\begin{array}{r}0.7840 * * * \\
(154.26)\end{array}$ & $\begin{array}{c}0.8631 * * * \\
(61.85)\end{array}$ \\
\hline Constant & $\begin{array}{r}-0.3941 \\
(-0.37)\end{array}$ & $\begin{array}{r}-0.3526 \\
(-0.10)\end{array}$ & $\begin{array}{r}-0.4073 \\
(-1.19)\end{array}$ & $\begin{array}{r}-0.4957 \\
(-1.55)\end{array}$ & $\begin{array}{c}-0.1183 * * * \\
(-6.51)\end{array}$ & $\begin{array}{c}-0.145^{* * *} * \\
(-4.98)\end{array}$ \\
\hline$A R(1) P$ & 0.0392 & 0.0431 & 0.1596 & 0.2633 & 0.0432 & 0.0690 \\
\hline $\operatorname{AR}(2) P$ & 0.1951 & 0.4444 & 0.9424 & 0.9375 & 0.8662 & 0.5813 \\
\hline Sargan P & 1.0000 & 1.0000 & 1.0000 & 1.0000 & 1.0000 & 1.0000 \\
\hline
\end{tabular}

\section{References:}

1. Fujita, M., Krugman, P., Venables, A.: The Spatial Economy and International Trade. MIT Press, Cambridge, MA (1999).

2. Glaeser, E., L.: Learning in Cities. Journal of Urban Economics, 46(2): 254-277(1999), DOI: 10.1006.19982121.

3. Krugman, P.: Geography and Trade. MIT Press, Cambridge, MA (1991).

4. Marshall, A.: Principles of Economics. London, Macmillan (1920).

5. O' Sullivan. A.: Urban Economics, 4th Edition. The McGraw-Hill Companies, Inc (2000).

6. Sanguinetti, P. Christian V., M.: Does Trade Liberalization Favour Industrial Concentration. mimeo, University National de La Plata, Argentina (2004). 